\title{
Pressure effect on crystallization kinetics in Zr46.8Ti8.2Cu7.5Ni10Be27.5 bulk glass
}

Jiang, Jianzhong; Gerward, Leif; Xu, Y.S.

Published in:

Applied Physics Letters

Link to article, DOI:

$10.1063 / 1.1527227$

Publication date:

2002

Document Version

Publisher's PDF, also known as Version of record

Link back to DTU Orbit

Citation (APA):

Jiang, J., Gerward, L., \& Xu, Y. S. (2002). Pressure effect on crystallization kinetics in Zr46.8Ti8.2Cu7.5Ni10Be27.5 bulk glass. Applied Physics Letters, 81(23), 4347-4349. https://doi.org/10.1063/1.1527227

\section{General rights}

Copyright and moral rights for the publications made accessible in the public portal are retained by the authors and/or other copyright owners and it is a condition of accessing publications that users recognise and abide by the legal requirements associated with these rights.

- Users may download and print one copy of any publication from the public portal for the purpose of private study or research.

- You may not further distribute the material or use it for any profit-making activity or commercial gain

- You may freely distribute the URL identifying the publication in the public portal

If you believe that this document breaches copyright please contact us providing details, and we will remove access to the work immediately and investigate your claim 


\title{
Pressure effect on crystallization kinetics in $\mathrm{Zr}_{46.8} \mathrm{Ti}_{8.2} \mathrm{Cu}_{7.5} \mathrm{Ni}_{10} \mathrm{Be}_{27.5}$ bulk glass
}

\author{
J. Z. Jianga) and L. Gerward \\ Department of Physics, Building 307, Technical University of Denmark, DK-2800 Lyngby, Denmark \\ Y. S. Xu \\ Bayrisches Geoinstitut, Universitaet Bayreuth, D-95440 Bayreuth, Germany
}

(Received 24 May 2002; accepted 10 October 2002)

\begin{abstract}
Crystallization kinetics of a $\mathrm{Zr}_{46.8} \mathrm{Ti}_{8.2} \mathrm{Cu}_{7.5} \mathrm{Ni}_{10} \mathrm{Be}_{27.5}$ bulk glass in the supercooled liquid region have been investigated by performing in situ high-temperature and high-pressure $\mathrm{x}$-ray diffraction measurements using synchrotron radiation. A pressure-time-temperature-transformation diagram, describing the onset of crystallization as a function of time during isothermal annealing under pressure, is presented. Different pressure dependences of crystallization kinetics in the temperature range for the glass have been observed and further be explained by a model of competing processes of the thermodynamic potential barrier of nucleation and the diffusion activation energy under pressure. (C) 2002 American Institute of Physics. [DOI: 10.1063/1.1527227]
\end{abstract}

Recently, after the discovery of several families of multicomponent alloys exhibiting a large supercooled liquid region before crystallization such as $\mathrm{La}-\mathrm{Al}-\mathrm{Ni}, \mathrm{Zr}-\mathrm{Al}-\mathrm{Cu}-\mathrm{Ni}$, and $\mathrm{Zr}$-Ti-Cu-Ni-Be systems, ${ }^{1-3}$ bulk metallic glass formation has become a common phenomenon. These novel materials possess an extremely high glass-forming ability and high thermal stability against crystallization, exhibiting excellent mechanical properties and good workability. ${ }^{4,5}$ They are potential engineering materials. For example, a cooling rate of only about $0.067 \mathrm{~K} / \mathrm{s}$ is required to suppress crystallization in a $\mathrm{Pd}_{42.5} \mathrm{Ni}_{7.5} \mathrm{Cu}_{30} \mathrm{P}_{20}$ alloy. ${ }^{6}$ The understanding of crystallization process of such alloys is of very high interest because it might shed light to the mechanism of high glassforming ability of the alloys. Furthermore, crystallization of metallic glasses is accompanied by significant changes in many properties. ${ }^{7}$ This imposes a strict limit on the operating times at elevated temperatures for such engineering materials. In this letter, we investigate the crystallization kinetics of a $\mathrm{Zr}_{46.8} \mathrm{Ti}_{8.2} \mathrm{Cu}_{7.5} \mathrm{Ni}_{10} \mathrm{Be}_{27.5}$ bulk glass, one of the most widely studied bulk metallic glasses, ${ }^{4}$ in the supercooled liquid region by performing in situ high-temperature and highpressure x-ray diffraction (XRD) measurements using synchrotron radiation. The pressure-time-temperaturetransformation (PTTT) diagram is presented, describing the onset of crystallization as a function of time during isothermal annealing under pressure. The issue of the pressure effect on crystallization of metallic glasses is of interest from a fundamental viewpoint, and also with respect to the applicability of these materials by deformation in the supercooled liquid region. ${ }^{8}$

Ingots of the $\mathrm{Zr}_{46.8} \mathrm{Ti}_{8.2} \mathrm{Cu}_{7.5} \mathrm{Ni}_{10} \mathrm{Be}_{27.5}$ bulk glass were produced by alloying the pure components by induction melting in a levitation device under purified $\mathrm{Ar}$ atmosphere and quenching by contact with water-cooled copper surface. This material was remelted in a fused silica crucible and die cast into a copper mold, to obtain $60 \mathrm{~mm}$ long rods with a diameter of $5 \mathrm{~mm}$. The average cooling rate was estimated to

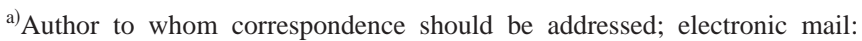
jiang@fysik.dtu.dk
}

be $>20 \mathrm{~K} / \mathrm{s}$. Samples from both ends of the rods were mechanically polished and analyzed by optical microscopy and scanning electron microscopy to ascertain the absence of undesirable primary crystals, which cannot be detected by XRD below a volume fraction of about 3\%. The thermal behavior of the glass was studied by a Perkin Elmers-Pyris1 differential scanning calorimetry (DSC) at a heating rate of $4 \mathrm{~K} / \mathrm{min}$ under a flow of purified argon. In situ high-temperature XRD measurements in a vacuum were performed using synchrotron radiation at beamline I711 at the MAXLAB in Lund, Sweden, utilizing a Huber G670 imaging plate Guinier camera. Each XRD pattern was accumulated for $2 \mathrm{~min}$. In order to exclude oxygen from the sample, the alloy was mounted on the top of a quartz capillary, which was pumped down to $10^{-4} \mathrm{~Pa}$ and then sealed. The temperature stability of the sample was $\pm 1 \mathrm{~K}$. In situ high-pressure and hightemperature energy-dispersive $\mathrm{x}$-ray diffraction measurements were performed using synchrotron radiation at HASYLAB in Hamburg, Germany. ${ }^{9}$ The cubic sample assembly is compressed by six truncation anvils of tungsten carbide in a 250 ton hydraulic press. Electric current is sent through a graphite heater via two appropriate anvils. The temperature is measured by means of thermocouple voltage with a stability of $\pm 1 \mathrm{~K}$. Both isothermal and nonisothermal experiments were performed. For isothermal experiments, the sample was first compressed to $2 \mathrm{GPa}$ at ambient temperature, rapidly heat up to a given temperature at a rate of $150 \mathrm{~K} / \mathrm{min}$ with an overshoot $<2 \mathrm{~K}$, and then kept the temperature and recorded XRD patterns for every 2 min. For nonisothermal experiments, each run consists of a room-temperature compression followed by an isobaric heating to high temperature in steps of $10 \mathrm{~K}$. The average heating rate in the temperature range from 25 to $550^{\circ} \mathrm{C}$ was roughly estimated to be $3 \mathrm{~K} / \mathrm{min}$. The pressure of the sample is calculated from lattice constant of $\mathrm{NaCl}$ using the Decker equation of state. ${ }^{10}$ Pure $\mathrm{Zr}, \mathrm{Fe}$, and the bulk metallic glass powders were used to examine the possible oxidation of samples during the heat treatments using the sample assembly. It was found that only pure metallic phases in the three systems were detected after heat treatments at temperatures up to $550^{\circ} \mathrm{C}$. For diffusion experi- 


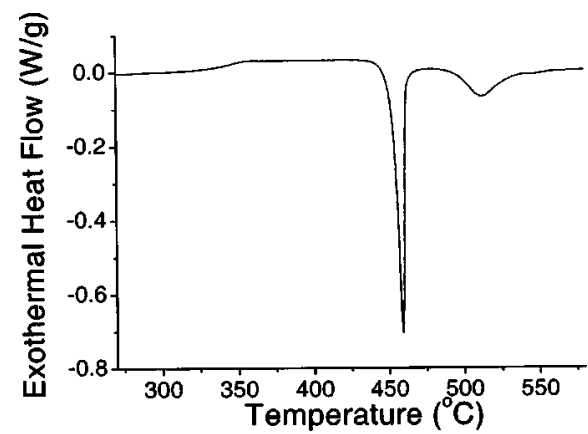

FIG. 1. The DSC curve of the $\mathrm{Zr}_{46.8} \mathrm{Ti}_{8.2} \mathrm{Cu}_{7.5} \mathrm{Ni}_{10} \mathrm{Be}_{27.5}$ bulk glass at a heating rate of $4 \mathrm{~K} / \mathrm{min}$ under a flow of purified argon.

ments, the measurements were carried out with relaxed $\mathrm{Zr}_{46.7} \mathrm{Ti}_{8.3} \mathrm{Cu}_{7.5} \mathrm{Ni}_{10} \mathrm{Be}_{27.5}$ samples, annealed at $310^{\circ} \mathrm{C}$ for $5 \mathrm{~h}$ in a vacuum of $10^{-6} \mathrm{~Pa}$, cut from cylindrical glass into slices of about $0.5 \mathrm{~mm}$ thickness and polished to a mirror finish on one side. The diffusing specie, Co, was implanted, in which the dose and implantation time were adjusted to reach a maximum concentration of Co less than 1 at. \% within a range of around $150 \AA$. Heat treatments of the samples at $380^{\circ} \mathrm{C}$ under four high pressures $(2,4,6$, and 8 $\mathrm{GPa}$ ) were performed in a multianvil press at the Bayerisches Geoinstitute. The diffusing specie concentration depth profiles of the as-implanted samples and the samples annealed at $380^{\circ} \mathrm{C}$ under different pressures were measured using secondary ion mass spectrometry. It was found that the samples annealed under pressures were slightly oxidized in a surface layer less than $10 \AA$, which does not affect the diffusion process here because the implanted Co layer is far below the oxidation surface layer.

Figure 1 shows the DSC trace of the $\mathrm{Zr}_{46.7} \mathrm{Ti}_{8.3} \mathrm{Cu}_{7.5} \mathrm{Ni}_{10} \mathrm{Be}_{27.5}$ bulk glass at a heating rate of 4 $\mathrm{K} / \mathrm{min}$. The glass exhibits an endothermic event characteristic of the glass transition at $T_{g}=330{ }^{\circ} \mathrm{C}$, followed by two exothermic events at $T_{x 1}=452{ }^{\circ} \mathrm{C}$ (the main heat release peak), $T_{x 2}=495^{\circ} \mathrm{C}$ (the small heat release peak), and $\Delta T$ $=T_{x 1}-T_{g}=122^{\circ} \mathrm{C}$. Figure 2 shows the PTTT diagram of the $\mathrm{Zr}_{46.8} \mathrm{Ti}_{8.2} \mathrm{Cu}_{7.5} \mathrm{Ni}_{10} \mathrm{Be}_{27.5}$ bulk glass, indicating the accessible times in the supercooled liquid region without crystallization for the glass. In this region, the glass exhibits viscous flow due to low viscosity. Applying pressure prolongs the time, i.e., enhances the operating time for deformation of the engineering material. How could external pressure retard the crystallization process? In our previous study, ${ }^{11}$ in the temperature region of $350-430^{\circ} \mathrm{C}$, the first transformed phase derived from the bulk glass by isothermal annealing is an icosahedral quasicrystal, i.e., the PTTT curves represent an amorphous-to-quasicrystalline phase transformation. At high temperatures, i.e., above $430^{\circ} \mathrm{C}$, the quasicrystalline phase is stable only for a short time period of less than $60 \mathrm{~s}$ and transfers into intermetallic compounds. ${ }^{11}$ In the present work, each XRD pattern is recorded for $120 \mathrm{~s}$. Thus, the PTTT curves at high temperatures, shown in Fig. 2, represent amorphous-to-quasicrystalline-to-intermetallic compounds, e.g, $\mathrm{Zr}_{2} \mathrm{Cu}, \mathrm{Be}_{2} \mathrm{Zr}$, etc.

The onset of these phase transformations is governed by the thermodynamic potential energy barrier of nucleation and the diffusion activation energy. According to crystallization kinetics theory, the nucleation rate, $I$, can be written as $I$

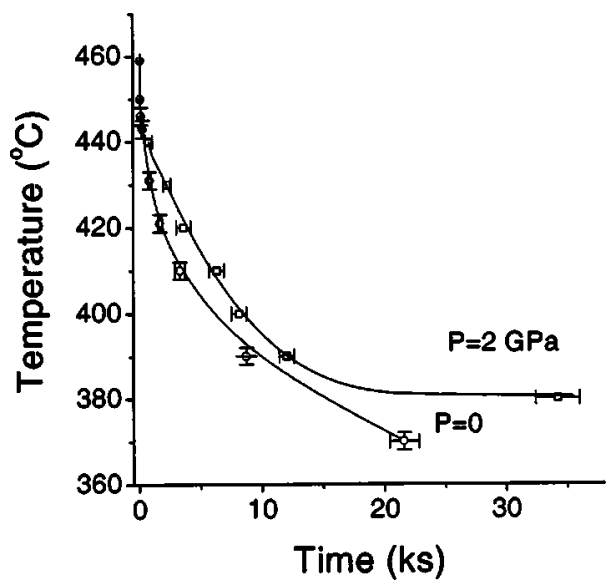

FIG. 2. The PTTT diagram of the $\mathrm{Zr}_{46.8} \mathrm{Ti}_{8.2} \mathrm{Cu}_{7.5} \mathrm{Ni}_{10} \mathrm{Be}_{27.5}$ bulk glass in the supercooled liquid region at pressures of 0 and $2 \mathrm{GPa}$. The solid lines are a guide for the eyes.

$=I_{o} / \exp \left[\left(\Delta G^{*}+Q_{n}\right) / k_{B} T\right]$, where $I_{o}$ is a constant, $\Delta G^{*}$ is the free energy required to form a nucleus of the critical size, i.e., the thermodynamic potential energy barrier of nucleation, $Q_{n}$ is the activation energy for the transport of an atom across the interface of an embryo, and $k_{B}$ is Boltzmann's constant. For the amorphous-to-quasicrystalline phase transformation, the interfacial energy of quasicrystals is usually small, e.g., $\sigma \sim 13 \mathrm{~mJ} / \mathrm{m}^{2}$ for $\mathrm{Zr}_{69.5} \mathrm{Al}_{7.5} \mathrm{Ni}_{11} \mathrm{Cu}_{12}$ alloy ${ }^{12}$ and $\sigma \sim 2-15 \mathrm{~mJ} / \mathrm{m}^{2}$ for $\mathrm{Al}_{75} \mathrm{Cu}_{15} \mathrm{~V}_{10}$ alloy. ${ }^{13} \Delta G^{*}$, which is proportional to $\sigma^{3} /(P \Delta V+\Delta G)^{2}$, could be negligible due to small $\sigma$ value, where $\Delta V$ and $\Delta G$ are the changes of molar volume and free energy between the phases involved. Thus, the nucleation rate of the formation of quasicrystals mainly depends on $Q_{n}$. We further performed diffusion measurements of $\mathrm{Co}$ (which is similar to $\mathrm{Ni}$ and $\mathrm{Cu}$ elements in the glass) in the bulk glass at $380^{\circ} \mathrm{C}$ under various pressures. The diffusion coefficient was deduced from the diffusing specie concentration depth profiles, as shown in Fig. 3. The diffusion coefficient at ambient pressure was extrapolated to be $1.6 \pm 0.2 \times 10^{-18} \mathrm{~m}^{2} / \mathrm{s}$ at $380^{\circ} \mathrm{C}$, which is in good agreement with the data, $1.3 \times 10^{-18} \mathrm{~m}^{2} / \mathrm{s}$, reported in literature. ${ }^{14}$ The diffusion coefficient decreases with pressure. Similar pressure dependence of $\mathrm{Ni}$ self-diffusion in the alloy was also reported. ${ }^{15}$ The activation volume was found to be 1.26 $\AA^{3}$, which corresponds to about one tenth of the Co atomic volume. It is usually assumed that large activation volume is interpreted as being indicative of a diffusion mechanism analogous to the single-jump vacancy mechanism. ${ }^{16}$ However, a collective motion was suggested for the diffusion

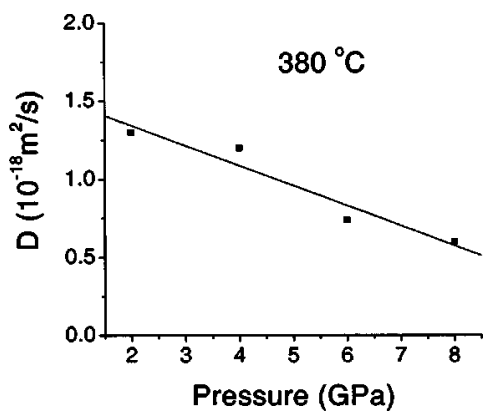

FIG. 3. Pressure dependence of the Co diffusion coefficient at $380{ }^{\circ} \mathrm{C}$ in the supercooled liquid region of the $\mathrm{Zr}_{46.7} \mathrm{Ti}_{8.3} \mathrm{Cu}_{7.5} \mathrm{Ni}_{10} \mathrm{Be}_{27.5}$ bulk glass. The

data were linearly fitted as a solid line.

to AIP license or copyright; see http://apl.aip.org/apl/copyright.jsp 


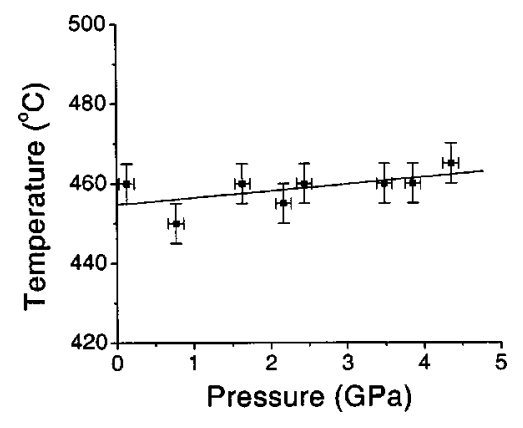

FIG. 4. The onset crystallization temperature of the bulk glass as a function of pressure, deduced from in situ high-temperature and high-pressure XRD measurements in steps of $10 \mathrm{~K}$ with an average heating rate of $3 \mathrm{~K} / \mathrm{min}$. The data were linearly fitted as a solid line with a slope of $1.7 \mathrm{~K} / \mathrm{GPa}$.

mechanism in the supercooled liquid region for the bulk metallic glasses. ${ }^{14,17}$ The small activation volume observed here confirms a collective motion governing the diffusion process in the supercooled liquid region of the glass. Therefore, $Q_{n}$ is expected to be enhanced with pressure. Consequently, the nucleation rate decreases with pressure so that a longer time is required for the onset of crystallization, in agreement with the observation in Fig. 2.

In the high-temperature region above $430{ }^{\circ} \mathrm{C}$, the crystallization becomes faster (Fig. 2). The pressure has a negligible effect, which is also confirmed by the pressure dependence of the onset crystallization temperature in Fig. 4 obtained by in situ high-temperature and high-pressure XRD measurements in steps of $10 \mathrm{~K}$ with an average heating rate of $3 \mathrm{~K} / \mathrm{min} .{ }^{18-23}$ The pressure effect on crystallization temperature is very small with a slope of $1.7 \mathrm{~K} / \mathrm{GPa}$ in the pressure range used. This is much smaller than the values reported in literature for metallic glasses, e.g., $30 \mathrm{~K} / \mathrm{GPa}$ for the $\mathrm{Fe}_{72} \mathrm{P}_{11} \mathrm{C}_{6} \mathrm{Al}_{5} \mathrm{~B}_{4} \mathrm{Ga}_{2}$ glass ${ }^{9}$ in the pressure range of $0-2.4$ $\mathrm{GPa}, 19 \mathrm{~K} / \mathrm{GPa}$ for the $\mathrm{Zr}_{41.2} \mathrm{Ti}_{13.8} \mathrm{Cu}_{12.5} \mathrm{Ni}_{10} \mathrm{Be}_{22.5}$ bulk glass $^{18}$ in the pressure range of $0-4 \mathrm{GPa}, 11 \mathrm{~K} / \mathrm{GPa}$ for the $\mathrm{Pd}_{40} \mathrm{Cu}_{30} \mathrm{Ni}_{10} \mathrm{P}_{20}$ bulk glass ${ }^{20}$ in the pressure range of $0-4$ $\mathrm{GPa}, 22 \mathrm{~K} / \mathrm{GPa}$ for $\mathrm{Zr}_{66.7} \mathrm{Pd}_{33.3}$ glass in the pressure range of $0-4 \mathrm{GPa},{ }^{21} 9.5 \mathrm{~K} / \mathrm{GPa}$ for the $\mathrm{Zr}_{48} \mathrm{Nb}_{8} \mathrm{Cu}_{14} \mathrm{Ni}_{12} \mathrm{Be}_{18}$ bulk glass $^{22}$ in the range of $0-4.4 \mathrm{GPa}$, and $16 \mathrm{~K} / \mathrm{GPa}$ for the $\mathrm{Mg}_{60} \mathrm{Cu}_{30} \mathrm{Y}_{10}$ bulk glass in the pressure range $0-4 \mathrm{GPa}^{23}$ This might be explained as follows. For the amorphous-toquasicrystalline-to-intermetallic compound transformations, $\Delta G^{*}$ for nucleation involves the interfacial energies between the intermetallic compounds and the supercooled liquid phase (and possibly crystalline/quasicrystalline interfaces) and $\Delta G$, the free energy difference between the supercooled liquid phase and the intermetallic compounds. $\Delta G^{*}$ for this new situation may be substantially greater than the activation energy for atomic diffusion, $Q_{n}$, due to larger interfacial energies for intermetallic compounds. ${ }^{24}$ On the other hand, $\Delta G$ of the glass in the supercooled liquid region, about 2.2 $\mathrm{kJ} / \mathrm{mol},{ }^{25}$ is much larger than the $P \Delta V$ term, about $0.1 \mathrm{~kJ} /$ $\mathrm{mol}$, for the pressure range used here assuming $0.5 \%$ volume contraction during the amorphous-to-polycrystalline phase transformation. ${ }^{26}$ Thus, $\Delta G^{*}$ is insensitive to pressure. This implies a weak pressure dependence of $T_{x}$, as observed experimentally in Fig. 4.

In conclusion, we present PTTT diagram in the super- cooled liquid region for the $\mathrm{Zr}_{46.8} \mathrm{Ti}_{8.2} \mathrm{Cu}_{7.5} \mathrm{Ni}_{10} \mathrm{Be}_{27.5}$ bulk glass, which is unknown in any other bulk metallic glassforming systems. Different pressure dependences of crystallization kinetics in the temperature range for the glass have been observed and further been explained by a model of competing processes of the thermodynamic potential barrier of nucleation and the diffusion activation energy under pressure.

The authors would like to thank HASYLAB in Hamburg, MAXLAB in Lund, and ESRF in Grenoble for use of the synchrotron radiation facilities. They would also like to thank P. X. Shi and T. J. Zhou for technical assistance during diffusion measurements and M.-P. Macht and N. Wanderka for providing the sample. Financial support from the Danish Technical Research Council, the Danish Natural Sciences Research Council, and the EU "IHP-Access to Research Infrastructures" program (Contract No. HPRI-1999-CT-00004 to D. C. Rubie) at the Bayerisches Geoinstitut is gratefully acknowledged.

${ }^{1}$ A. Inoue, T. Zhang, and T. Masumoto, Mater. Trans., JIM 31, 425 (1990).

${ }^{2}$ T. Zhang, A. Inoue, and T. Masumoto, Mater. Trans., JIM 32, 1005 (1991).

${ }^{3}$ A. Peker and W. L. Johnson, Appl. Phys. Lett. 63, 2342 (1993).

${ }^{4}$ W. L. Johnson, MRS Bull. 24, 42 (1999).

${ }^{5}$ A. Inoue, Acta Mater. 48, 279 (2000).

${ }^{6}$ N. Nishiyama and A. Inoue, Appl. Phys. Lett. 80, 568 (2002).

${ }^{7}$ Amorphous Metallic Alloys, edited by F. E. Luborsky (Butterworths, London, 1983).

${ }^{8}$ T. Zumkley, S. Suzuki, M. Seidel, S. Mechler, and M.-P. Macht, Mater. Sci. Forum 386, 541 (2002).

${ }^{9}$ J. Z. Jiang, J. S. Olsen, L. Gerward, S. Abdali, J. Eckert, N. Schlorke-de Boer, L. Schultz, J. Truckenbrodt, and P. X. Shi, J. Appl. Phys. 87, 2664 (2000).

${ }^{10}$ D. L. Decker, J. Appl. Phys. 42, 3239 (1971).

${ }^{11}$ N. Wanderka, M.-P. Macht, M. Seidel, S. Mechler, K. Ståhl, and J. Z. Jiang, Appl. Phys. Lett. 77, 3935 (2000).

${ }^{12}$ U. Koster, J. Meinhardt, S. Roos, and R. Busch, Mater. Sci. Eng., A 226, 995 (1997).

${ }^{13}$ J. C. Holzer and K. F. Kelton, Acta Metall. 39, 1833 (1991).

${ }^{14}$ H. Ehmler, A. Heesemann, K. Ratzke, and F. Faupel, Phys. Rev. Lett. 80, 4919 (1998)

${ }^{15}$ K. Knorr, M.-P. Macht, K. Freitag, and H. Mehrer, J. Non-Cryst. Solids 250, 669 (1999).

${ }^{16}$ For example, see F. Faupel, P. W. Huppe, and K. Ratzke, Phys. Rev. Lett. 65, 1219 (1990); A. Grandjean and Y. Limoge, Acta Mater. 45, 1585 (1997).

${ }^{17}$ X. P. Tang, U. Geyer, R. Busch, W. L. Johnson, and Y. Wu, Nature (London) 402, 160 (1999).

${ }^{18}$ J. Z. Jiang, T. J. Zhou, H. K. Rasmussen, U. Kuhn, J. Eckert, and C. Lathe, Appl. Phys. Lett. 77, 3553 (2000).

${ }^{19}$ Y. X. Zhuang, J. Z. Jiang, T. J. Zhou, H. Rasmussen, L. Gerward, M. Mezouar, W. Crichton, and A. Inoue, Appl. Phys. Lett. 77, 4133 (2000).

${ }^{20}$ J. Z. Jiang, Y. X. Zhuang, H. Rasmussen, N. Nishiyama, A. Inoue, and C. Lathe, Europhys. Lett. 54, 182 (2001).

${ }^{21}$ J. Z. Jiang, K. Saksl, J. Saida, A. Inoue, H. Franz, K. Messel, and C.Lathe, Appl. Phys. Lett. 80, 781 (2002).

${ }^{22}$ Y. X. Zhuang, L. Gerward, J. Z. Jiang, J. S. Olsen, Y. Zhang, and W. H. Wang, Mater. Res. Soc. Symp. Proc. 644, L5.2.1 (2001).

${ }^{23}$ S. Linderoth, N. Pryds, M. Eldrup, A. S. Pedersen, M. Ohnuma, T. J. Zhou, L. Gerward, J. Z. Jiang, and C. Lathe, Mater. Res. Soc. Symp. Proc. 644, L4.1.1 (2001).

${ }^{24}$ J. Z. Jiang, Y. X. Zhuang, H. Rasmussen, J. Saida, and A. Inoue, Phys. Rev. B 64, 094208 (2001).

${ }^{25}$ R. Busch, JOM 52, 39 (2000); R. Busch, E. Bakke, and W. L. Johnson, Mater. Sci. Forum 235, 327 (1997).

${ }^{26}$ A. Inoue, T. Negishi, H. M. Kimura, T. Zhang, and A. R. Yavari, Mater. Trans., JIM 39, 318 (1998); H. S. Chen, Rep. Prog. Phys. 43, 353 (1980). 